\title{
Libertários e tutelares no mundo do trabalho
}

\author{
ANTONIO DAVID CATTANI
}

RESUMO: Durante a Revolução Francesa, explicitaram-se duas concepções e práticas relativas à organização dos trabalhadores e à sua participação na esfera política e cujo legado chegou também ao Brasil. Formas específicas de Jacobinismo ou Cesarismo Social e de "Sociabilidade Associativa" confrontaram-se durante todo o período republicado com claro predomínio das práticas tutelares sobre as tentativas de autodeterminação proletária. As manifestações modernas de paternalismo autoritário e de solidariedade mutualista são desafiadas no Brasil contemporâneo pela existência de profundas desigualdades sociais e econômicas.

\section{Introdução}

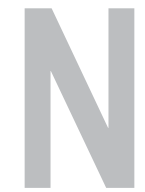

os últimos dois séculos, a esfera da produção material assumiu um papel preponderante no agenciamento da vida social com conseqüências diretas sobre a organização política das sociedades ocidentais. Os confrontos capital-trabalho no processo produtivo e as disputas pela apropriação do excedente não se materializam apenas no âmbito das empresas. O mundo do trabalho, longe de ser um espaço apaziguado - regido por princípios utilitaristas, harmoniosos e racionais de exclusivo domínio privado - é um permanente campo de batalha no qual se confrontam concepções e projetos que vão além do ambiente propriamente fabril. Para compreender a dinâmica econômica

PALAVRAS-CHAVE: Revolução Francesa, trabalho, jacobinismo, proletariado.
Professor do departamento de sociologia da IFCH - UFRGS 
${ }^{1}$ Mais do que a tomada da Bastilha, referência simbólica do início da revolução, o Juramento do Jeu de Paume ("jamais se separar antes de definir uma constituição soberana para reger os destinos do país"), sinaliza a determinação cívica e consciente de, custe o que custar, levar adiante o processo de superação do antigo regime. e social contemporânea, é necessário considerar, portanto, os múltiplos condicionamentos históricos, a correlação de forças na esfera pública e as ações desenvolvidas pelo Estado.

Neste artigo procuraremos destacar de maneira sintética dois movimentos políticos que buscaram e que, continuamente, buscam implementar lógicas especificas de organização social, em especial no que concerne ao agenciamento dos produtores diretos, dos trabalhadores e, através deles, da grande maioria da população.

Estes dois movimentos são coetâneos do capitalismo mas sua explicitação foi particularmente exemplar durante a Revolução Francesa. A partir de então, por caminhos tortuosos, esses projetos aparecem recorrentemente na histórica econômica e social dos países ocidentais. No caso brasileiro, eles manifestaram-se de maneira tão forte que explicam facetas importantes da nossa história social e política.

\section{Os legados da Revolução Francesa}

Entre o Juramento do Jeu de Paume (junho de 1789) ${ }^{1}$ e o golpe de Estado do 18 Brumário (novembro de 1799), passaram-se apenas dez anos e poucos meses: um curtíssimo espaço de tempo durante o qual ocorreram os mais prodigiosos acontecimentos políticos da história humana recente.

A aceleração do tempo histórico, a densidade dos fatos políticos, o avanço teórico na construção de novos valores na última década do século XVIII foram sem precedentes. Represados ao longo do século, os devaneios utopistas, os avanços intelectuais da República das Letras, a busca da autonomia das lojas maçônicas, a insatisfação difusa do proletariado e o projeto político da classe burguesa emergente, abruptamente, encontraram um espaço de vazão. O que antes era utópico, abstrato, virtual, transformou-se em ação concreta.

Em um movimento ascendente do processo civilizatório, a força revolucionária arrancou os dormentes da letargia, quebrou as amarras embrutecedoras da dominação da nobreza, superou a mediocridade opressora do absolutismo já fora do seu tempo. A razão se irradiou, a liberdade encontrou na França seu território. O poder absolutista, supra sumo da arbitrariedade, cedeu lugar ao contrato social. A religião institucionalizada, igualmente opressora e obscurantista, foi sendo substituída pela sociedade secular e dessacralizada.

A ruptura com o Antigo Regime e sua superação foram processos de acelerada criação histórica permitindo sair do discurso, das idéias e dos ideais, para a prática concreta, a ação transformadora. A ação coletiva permitiu forjar a Nação como processo consciente e deliberado, associar a liberdade moral à liberdade material, distinguir Poder e Direito, enfim, permitiu fazer com que o indivíduo passasse a existir como cida- 
dão. O que antes eram apenas declarações de princípios abstratos passou a ser objetivado na realidade. No mais rico avanço inspirado no Século das Luzes, o indivíduo passou a ser entendido como um sujeito natural de direito, um ser livre de toda tirania, de toda relação de avassalamento. Ao abolir o sujeito do rei permitindo o surgimento do sujeito de direito (sujet du roi x sujet de droit), elaboraram-se os princípios da democracia igualitária, reforçados pelo que ela tem de mais revolucionário: o direito de resistência. Para garantir a liberdade, os cidadãos têm o direito de se revoltar. Toda luta contra a opressão é justificada, toda resistência à tirania é justa, toda revolução para ampliar a liberdade é legítima.

O primeiro ato revolucionário é a declaração tonitruante dos Direitos Humanos estruturados pelos princípios cívicos de Liberdade e Igualdade. Estas duas idéias-força, acrescidas, a partir de 1792, do princípio da Fraternidade, pela sua audácia, pela sua generosidade e positividade, ganharam o mundo e são o legado mais precioso e civilizatório da Revolução. Afïrma-se através delas a ascensão possível do gênero humano, a negação da violência, das tutelas paternalísticas, messiânicas ou despóticas, a negação dos personalismos aristocráticos ou caudilhescos, do racismo, dos preconceitos, das prerrogativas e privilégios que compõe o submundo dos particularismos excludentes (cf. Cattani, 1991).

Cidadania e democracia que dão consistência aos princípios de Liberdade, Igualdade e Fraternidade reafirmam a potencialidade criadora da humanidade além dos limites impostos pela geografia, pelos nacionalismos estreitos, pelos pseudo-determinismos das estruturas materiais autoreferentes. A ampliação da liberdade e do conhecimento desta liberdade, os princípios de justiça, de respeito ao outro, de respeito fraterno à sua liberdade e diferença são os legados universais da Revolução Francesa. Os seus princípios cívicos, suas idéias-força são, 200 anos depois, um patrimônio moral da humanidade de completa e inarredável atualidade.

Porém, ainda durante a Revolução, as tentativas de objetivar tais princípios configuraram-se em práticas distintas, orientando experiências históricas repetidas ao longo de dois séculos. Entre as múltiplas dimensões e entre os complexos desdobramentos sociais e ideológicos daquela década prodigiosa, é possível destacar as realizações de duas correntes políticas no que tange o mundo do trabalho.

Estas concepções e realizações dizem respeito aos trabalhadores e ao movimento sindical também no Brasil. Não se trata de transmissão de uma herança direta ou de filiações intelectuais precisas que poderiam ser ilustradas por exemplos pontuais. O objetivo deste texto será o de destacar princípios e práticas políticas paradigmáticas e cuja origem pode ser identificada em dois acontecimentos marcantes entre 1792 e 1796. Refiro-me ao surgimento do Jacobinismo e da proposta de "Sociabilidade Associativa" formulada por Gracchus Babeuf.

Estes dois movimentos políticos - distintos da lógica e da práti- 
*A data entre colchetes refere-se sempre à edição original da obra. Ela é indicada na primeira vez que a obra é citada. Nas demais, indica-se somente a edição utilizada pelo autor (nota do Editor). ca liberais e neoliberais - manifestaram-se de forma recorrente e concorrente ao longo dos dois últimos séculos, não só na França mas em diversos países, inclusive no Brasil.

Gramsci refere-se ao Jacobinismo como uma manifestação de Cesarismo Social, isto é, um regime político consubstanciado no poder estatal, cuja legitimidade é construída por um homem de confiança das massas e dos corpos organizados que se submetem a ele para evitar conflitos estéreis. No Cesarismo é comum a eliminação das instituições intermediárias, impedindo-se qualquer manifestação da soberania popular. Os jacobinos representam a profissionalização de militantes auto-investidos da missão política de controlar o Estado para atender aos interesses das massas. O organismo político, austero e puritano, viabiliza-se como ditadura da virtude, messianicamente responsável pela redenção proletária e pela salvação da pátria (cf. Bongiovanni, 1986).

No ano da hegemonia política jacobina, Robespierre discursa na Convenção (10/05/1793):

"O homem nasceu para a felicidade e para a liberdade, entretanto, ele é escravo e infeliz. A sociedade tem como objetivo a conservação dos seus direitos e o aperfeiçoamento do seu ser e, em todos os lugares a sociedade o degrada e o oprime. Chegou o momento de lembrá-la dos seus verdadeiros destinos: os progressos da razão humana prepararam esta grande Revolução e é sobre vocês que é imposto o dever de acelerá-la. Até agora a arte de governar resumiu-se à arte de explorar $e$ de submeter a maioria em proveito da minoria. Reis e aristocratas defenderam bem seus interesses. Cabe a vocês mudar a situação. Isto é, fazer os homens felizes e livres através das leis” (Robespierre, 1965).

Altruísmo, abnegação, ética social, racionalidade operosa, heroísmo voluntarista caracterizam, originalmente, a luta jacobina contra o conservadorismo e contra o status quo. Mas, como corrente política, sua descendência trilhou caminhos tortuosos: elitismo tecnocrático de Saint Simon e de vários positivistas, paternalismo autoritário de inúmeros caudilhos, vanguardas leninistas. Um século depois de Robespierre, Lenin enaltece os quadros impolutos

“...capazes de tomar o poder e conduzir todo o povo ao socialismo, de dirigir e organizar um novo regime e de ser o instrutor, o guia e o chefe de todos os trabalhadores" (Lenin, [1917] 1983)*.

A tradição jacobina conjuga-se também nas múltiplas formas operativas dos quadros do Estado de Bem Estar através de políticas 
keynesianas ou social-democratas, que buscam promover, desde o alto, a integração das massas, a promoção do bem comum mesmo que seja à revelia dos interessados.

A Sociabilidade Associativa tem seu momento fundante no Manifesto dos Plebeus (novembro de 1795) e na trágica Conjuração dos Iguais (1796). Babeuf defendia a igualdade de fato que conjugaria os três princípios da Revolução. A igualdade perfeita passa pelo "estabelecimento da administração popular, pela supressão da propriedade privada, pela vinculação de cada indivíduo ao seu talento, fazendo-o depositar os frutos do seu trabalho em um espaço coletivo, estabelecendo uma administração única dos bens que assegurará a sua repartição segundo a mais escrupulosa igualdade." (Babeuf, [1795] 1977)

Os princípios da Propriedade Comum, da Democracia Direta e da Fraternidade Igualitária e da conseqüente recusa da exclusão, seriam viabilizados pela "Sociabilidade Associativa", outro nome para a comunidade comunista.

Da mesma forma que o Jacobinismo, o Babouvismo não se resumiu à declarações de princípios e de intenções. As iniciativas de organização social autenticamente comunista multiplicaram-se ao longo dos séculos XIX e XX. O legado de Babeuf e dos seus companheiros foi incorporado por grupos heteróclitos e, por vezes, antinômicos: falanstérios, cooperativas de produção, associações mutualistas, agrupamentos anarquistas e outras experiências de autogestão. Ele materializou-se em microcomunidades libertárias, na Comuna de Paris, nos Sovietes russos do início do século, nos Conselhos Operários italianos nos anos 20 e em experimentos sociais de auto-organização proletária em vários países.

Pelo salto teórico proporcionado, pela paixão intensa no período da sua manifestação histórica, a curta hegemonia jacobina e a efêmera Conjuração dos Iguais podem ser consideradas como momentos fundantes de dois caminhos que constituem matrizes de relações sociais e políticas que vigoram até hoje. De um lado, a concepção e as práticas dirigistas tentando realizar a vontade geral através da ação da minoria atuante, de outro, os ideais de autonomia, de livre organização e de autogestão.

A partir dessas duas matrizes básicas, de caráter universal, é possível captar processos gerais que ocorreram no nosso país, especialmente no que concerne às lutas e à organização do trabalho no período Republicano.

1889-1930 - Tentativas de autodeterminação proletária

A República Velha, marcada pela permanente contradição en- 
tre o discurso liberal e as práticas autoritárias, pode ser caracterizada como um período de livre experimentação social no mundo do trabalho. As elites detinham o controle da situação política e econômica, mas, por todos os lados, os trabalhadores estavam se organizando de forma espontânea e autônoma. A legislação social era permissiva e, mesmo que fosse de forma incipiente, multiplicavam-se as organizações independentes: sociedades mutualistas, sindicatos, comitês de defesa proletária, centros operários, etc. A formalização jurídica era imprecisa, as iniciativas sindicais articulavam a defesa dos interesses de classe com a promoção da cultura e do lazer.

A forte influência do anarco-sindicalismo potencializava a dimensão libertária e a afirmação de uma identidade autônoma, não subserviente à burguesia e resistente às tentativas de controle por parte do Estado. A repressão implementada pelas classes proprietárias, bem como as tentativas de disciplinar o proletariado segundo a racionalidade produtivista da burguesia industrial, foram consideradas como estratégias reativas por conceituados analistas (cf. Gomes, 1979; Santos, 1978). Em outros termos, durante a República Velha o proletariado tomava a iniciativa, buscava viabilizar a construção histórica segundo princípios de autoproteção e auto-organização segundo seus interesses difusos, enquanto que as classes proprietárias buscavam, por todos os modos, impedir o progresso da ação coletiva dos subalternos.

O movimento era débil e as experiências verdadeiramente autônomas foram raras, mas podemos afirmar que, no espírito do tempo, os ideais libertários e os princípios da auto-organização possuíam ampla legitimidade dentro da classe operária mais organizada.

\section{0-1988 - A tutela sobre os “incapazes”}

As forças políticas vitoriosas na Revolução de 1930 possuíam outras concepções sobre a participação política dos subalternos. No reordenamento das relações sociais através do processo de crescimento industrial, a participação autônoma das massas não era admitida.

O projeto varguista é uma ilustração iniludível do Cesarismo Social. Segundo a concepção das elites que tomaram o poder, cumpria ao Estado, entendido como instituição acima e à frente dos interesses localizados e limitados das classes sociais, "fazer progredir o povo" (Gomes, 1988, p. 243).

"As leis sociais com que o atual Governo, por iniciativa própria, tem procurado amparar as classes trabalhadoras, atendem às justas aspirações do povo” (Vargas, 1938, p. 205).

"Quais as aspirações das massas obreiras, quais os seus interesses? Eu vos responderei: A ordem e 
o trabalho!" (Gomes, 1988, p.171).

O "povo" era entendido como incapaz de tomar iniciativa, de promover o seu interesse, de lutar pela sua promoção, carecendo, pois, da proteção, da tutela do pai dos pobres. O nume tutelar respaldado na razão e nos bons sentimentos outorga a cidadania, concede as normas e leis que organizam os trabalhadores, protegendo sensata e benevolamente o petit peuple.

O dirigismo tutelar perdurou por mais de meio século, ajustando-se pragmaticamente à orientação dos regimes que se sucederam: "democracia autoritária" no Estado Novo, "compromisso com a causa trabalhadora" nos governos populistas, "capitalismo social" na ditadura burocrático-militar, resultando na domesticação dos sindicatos (cf. Freitas, 1989), ou no que Armando Boito Jr. (1991) classificou como sendo um verdadeiro "sindicalismo de Estado".

O resultado da tutela estatal foi o desmantelamento das entidades autônomas e o condicionamento da mentalidade popular; os trabalhadores desacreditaram da sua própria capacidade de luta e passaram a esperar da autoridade benevolente, a cidadania e os benefícios sociais em uma percepção que não ia além do interesse localizado e limitado de cada individualidade ou, no máximo, de cada categoria profissional.

Desde Lindolfo Collor, os Ministros do Trabalho passaram a repetir a mesma litania: a greve não é oportuna, são atos de baderna, os trabalhadores não precisam de comissões de fábrica, a irrupção do movimento sindical no processo político prejudica a democracia, o Governo está fazendo o que é necessário, etc.

As boas intenções dos dirigentes são explicitadas continuamente para construir a legitimidade da tutela. Getúlio Vargas "construiu para o povo um monumento legislativo de dignificação do trabalho humano" (Gomes, 1988, p. 240); o Governo "faz tudo pelo Social" (slogan da Nova República"); o Presidente, "identificando-se com a índole pacífica e ordeira do povo humilde, está criando as condições para lhe assegurar a prosperidade e a liberdade com leis justas" (Fernando Henrique Cardoso em pronunciamento em abril de 1995).

Esta última frase pode aproximar-se da conclamação de Robespierre aos convencionais de 1793, mas, obviamente não cabe nenhuma comparação entre FHC e o Incorruptível! O que cabe destacar é a mentalidade das elites brasileiras, conservadoras ou progressistas, sua incapacidade de imaginar os subalternos capazes de forjar seu próprio destino, pois são caracterizados por possuírem uma "timidez social inata" (Gomes, 1988, p. 270), pela falta de vontade e de civismo, por não terem capacidade nem maturidade para avançar no processo democrático (cf. Pécaut, 1990). Apenas as elites possuidoras da consciência esclarecida, que adotam estratégias de compromisso no Estado ou nos partidos políticos, podem dirigir tutelarmente a massa de ignaros, reprimir os equivo- 
cados do MST, os irresponsáveis do movimento sindical.

"Senhor, perdoai-os porque não sabem o que fazem" (Fernando Henrique Cardoso dirigindo-se ao senador Antonio Carlos Magalhães durante protesto popular na Bahia em 1995).

\section{Liberdade e Fraternidade sem Igualdade?}

Fazendo-se um balanço entre as tentativas libertárias e as práticas tutelares sobre o mundo do trabalho no Brasil, o resultado pende, claramente, para o lado autoritário, seja ele implementado pelo Cesarismo Social, pelo paternalismo autoritário, pelo populismo caudilhesco ou ainda pelo elitismo progressista.

O surgimento dos novos movimentos sociais nos últimos 20 anos parece contradizer afirmação tão severa. Efetivamente, desde o início dos anos 80 observa-se a reorganização dos movimentos populares sob a bandeira da liberdade e da autonomia, multiplicam-se as associações das classes desfavorecidas e de segmentos específicos da sociedade civil (luta por moradia, por direitos humanos, organizações ecológicas, feministas, de minorias, antiviolência, as redes cidadãs, etc.). A constituição de 1988 restabeleceu alguns princípios elementares da liberdade e da autonomia sindical cuja efetivação ainda está, entretanto, condicionada ao peso da herança do modelo tutelar.

No Brasil, ocorre um dos mais extraordinários movimentos sociais da contemporaneidade: o Movimento dos Trabalhadores Sem Terra, cujo ideário e práticas identificam-se plenamente com o Manifesto dos Plebeus redigido por Babeuf e seus companheiros (uma comparação muito interessante pode ser feita entre a origem social, a trajetória profissional e as concepções políticas de Gracchus Babeuf e de João Pedro Stédile).

As múltiplas realizações no campo da economia solidária concretizam o princípio da organização autônoma dos produtores diretos, reeditando a utopia autogestionária de Owen, Fourier e Proudhon. As novas cooperativas aproximam-se da solidariedade mutualista que dignificou a classe trabalhadora ao longo dos séculos (cf. Singer, 2000).

As administrações populares de esquerda avançam em todo o pais, redefinindo a participação cidadã, em esferas que antes eram domínio privado dos feudos políticos, da tecnocracia e do poder econômico.

A ampliação dessas práticas está anulando os efeitos do dirigismo tutelar? Está ampliando os espaços de realização da autonomia proletária? Sim, claramente sim! Por todos os lados, observa-se a aplicação de duas das palavras do trinômio da Revolução Francesa: avança a liberdade e avança, embora mais lentamente, a solidariedade, que é o equivalente contemporâneo da Fraternidade. O avanço ocorre nos interstícios do poder, nas franjas da sociedade, garantindo uma lenta expansão dos espaços de liberdade. A cidadania passa, gradualmente, a ser entendida como con- 
quista e não como concessão, fundamentando-se em princípios jurídicos com legitimidade inquestionável. Porém, esta evolução positiva não deve obnubilar a ausência da terceira idéia-força e ideal da Revolução: a IGUALDADE.

Histórica e estruturalmente, o Brasil caracteriza-se por índices extremos de múltiplas desigualdades. São raras as iniciativas sociais que contrapõem-se de maneira consistente e abrangente ao processo gerador da desigualdade e da injustiça sociais. Pode-se falar da igualdade como expressão de valores morais e éticos, como aspiração e virtude de uma sociedade que visa o bem comum, mas tanto quanto Liberdade e Solidariedade ela só tem consistência enquanto realização concreta, enquanto efetivação das regras de distribuição (cf. Oppenheim, 1986).

Neste sentido, no Brasil, ainda não chegamos em 1789!

A matriz das relações sociais e econômicas reproduz e amplia continuamente a desigualdade. As instituições que poderiam modificar este quadro desenvolvem ações insuficientes. Referimo-nos especificamente às organizações sindicais que, historicamente, disseram respeito e concernem ainda hoje aos indivíduos que estão longe de ocupar os degraus mais baixos da escala social. Ou seja, apesar da combatividade em vários momentos históricos (1953-1954, 1961-1964, 1978-1988), o movimento sindical não conseguiu articular a defesa dos interesses corporativos dos trabalhadores formais com as necessidades dos excluídos, dos desempregados, dos trabalhadores do setor informal, que representam mais de $60 \%$ da população economicamente ativa.

As demais entidades da sociedade civil, sejam elas as formas clássicas (como os partidos, as associações de profissionais liberais, etc.) sejam as contemporâneas (ONGS), padecem de uma incapacidade congênita: a de não conseguirem ampliar o espírito associativo. Multiplicam-se as instituições, mas o número de associados é irrisório. Estima-se que menos de $1 \%$ da população participe da vida associativa (cf. Demo, 1991), índice que nos países economicamente mais desenvolvidos é, no mínimo, oito vezes maior.

$\mathrm{O}$ individualismo como traço cultural, como sintoma dos condicionamentos históricos que forjaram comportamentos subservientes, constitui uma barreira poderosa impedindo o igualitarismo e, por extensão, o apreço aos outros valores cívicos. A verdadeira liberdade jamais é um exercício individual. $\mathrm{O}$ antiassociativismo corrompe a Fraternidade, transformando-a em assistencialismo ou em caridade (cf. Geremek, 1978). O antiassociativismo é terreno propício para as práticas tutelares. Amplia o isolamento dos indivíduos e sua vulnerabilidade, acabando por gerar um pragmatismo acomodatício. E em uma sociedade tão desigual e tão hierarquizada não faltam candidatos a chefe, a guias para "conduzir o rebanho ao bom caminho".

Este é o grande desafio que o país enfrenta no limiar de um 
novo milênio. Como ampliar a Solidariedade e a Liberdade, quando a exclusão aumenta, quando desemprego e a precariedade multiplicam os dependentes, os subalternos, os sem autonomia, quando a luta pela Igualdade não está na pauta política, ou quando está na agenda dos movimentos, sociais, mas estes não contam com a adesão dos cidadãos?

Mas tais constatações, provenientes do realismo fundado no conhecimento científico, não anulam o espírito utópico dos libertários. Por todos os lados, multiplica-se incessantemente a coragem de mudar e a vontade de lutar contra o conformismo, a apatia e a vassalagem, fundamentos da servidão voluntária. Ao realismo cínico do paternalismo autoritário ou às boas, porém equivocadas, intenções dos dirigentes tutelares, contrapõem-se a utopia possível dos autonomistas, a perene mobilização daqueles que lutam para construir uma sociedade mais livre, mais justa e mais solidária. A mobilização utópica possui um argumento convincente: se nas circunstâncias infinitamente mais desfavoráveis da dominação absolutista e clerical foi possível mudar a sociedade de maneira radical e afirmar os princípios de Liberdade, Igualdade e Fraternidade, podemos, hoje, queixar-nos e contentar-nos com menos do que foi sonhado e realizado há mais de 200 anos?

Recebido para publicação em dezembro/2001

KEYWORDS:

French revolution, labor, Jacobinism, workers.
CATTANI, Antonio David. Libertarians and tutors in the world of work. Tempo Social, Rev. Sociol. USP, S. Paulo, 14(2): 71-81, October 2002.

ABSTRACT: During the French Revolution, two conceptions and practices associated to worker organization and to their participation on the political sphere, whose legacy also reached Brazil, became explicit. Specific forms of Jacobism or Social Cesarism and of "Associative Sociability" confronted themselves during the entire republican period, with the predominance of tutelary practices over proletarian auto determination attempts. The modern manifestations of authoritarian paternalism and mutual solidarity are defied in contemporary Brazil by profound social and economic inequalities.

\section{REFERÊNCIAS BIBLIOGRÁFICAS}

BABEuf, Gracchus. (1977) Textes Choisis. Original de 1795. Paris, Éditions Sociales. 
Bongiovanni, Bruno. (1986) Jacobinismo. In: BobBio et alli. (org.). Dicionário de Política, Brasilia, UNB.

Borto Jr., Armando. (1991) Sindicalismo de Estado no Brasil. São Paulo, Hucitec.

CAtTAni, Antonio David. (1991) A ação coletiva dos trabalhadores. Porto Alegre, SMCultura, Palmarinca.

Demo, Pedro. (1991) Cidadania menor. Petrópolis, Vozes.

Freitas JR, Antonio. (1989) Sindicado: domesticação e ruptura. São Paulo, OAB Editorial.

GEREMEK, Bronislaw. (1978) A piedade e a forca. Lisboa, Terramar, 1988.

Gomes, Angela de Castro.(1979) Burguesia e trabalho. São Paulo, Campus.

. (1988) A invenção do trabalhismo. Rio de Janeiro, Vértice.

LENIN, Vladimir. (1983) O Estado e a Revolução. Edição original 1917. São Paulo, Hucitec.

OpPenheIm, Félix. (1986) Igualdade. In: BobBio et alli. (org.). Dicionário de Política, Brasília, UNB.

PÉcAut, Daniel. (1990) Os intelectuais e a política no Brasil. São Paulo, Ática.

RoBesPIERRE, Maxilimien. (1965) Discours et rapports à la Convention. Paris, UGE 10-18.

SAntos, Wanderley Guilherme dos. (1978) Ordem burguesa e liberalismo político. São Paulo, Duas Cidades.

Singer, Paul. (2000) A economia solidária no Brasil. São Paulo, Contexto.

VArgas, Getúlio. (1938) A nova política no Brasil. Vol V. Rio de Janeiro, José Olympio. 